\title{
An EOQ Model for A Deteriorating Item With Time Dependent Exponentially Declining Demand Under Permissible Delay In Payment
}

\author{
${ }^{1}$ Trailokyanath Singh, ${ }^{2}$ Hadibandhu Pattanayak., \\ ${ }^{1}$ (Department of Mathematics, C. V. Raman College of engineering, Bhubaneswar, Odisha, India) \\ ${ }^{2}$ (Department of Mathematics, Sailabala Women's College, Cuttack, Odisha, India)
}

\begin{abstract}
In this study, an EOQ (Economic Order Quantity) inventory mathematical model is constructed for a deteriorating item having time dependent demand when delay in payment is permissible. The deterioration rate is assumed to be a constant and the time varying demand rate is taken to be an exponential declining function of time. Mathematical models are also derived under two different circumstances, that is, Case I: The credit period is less than or equal to the cycle time for setting the account and Case II: The credit period is greater than the cycle time for setting the account. Numerical examples are provided to illustrate the model and the sensitivity analysis is also studied.
\end{abstract}

Keywords:-Deterioration Exponential declining demand, Inventory, Permissible delay in payment.

\section{Introduction}

In the past few decades, inventory problems for deteriorating items have been widely studied. Most of the physical goods deteriorate over time. In reality, some of the items either decayed or deteriorated or damaged or vaporized or affected by some other factors and are not in a perfect condition to satisfy the demand. Food items, grains, vegetables, fruits, drugs, pharmaceuticals, radioactive substances, fashion goods and electronic substances are a few examples of such items in which sufficient deterioration can take place during the normal storage period of the units and consequently this loss must be taken into account when analyzing the system. Therefore, the loss due to deterioration cannot be neglected. In formulating the inventory models, two factor of the problem have been growing interest to the researchers, one being the deterioration of the items and the other being the variation in the demand rate. In real life situation, demand is the major factor in the inventory management. Therefore, researchers have recognized and studied the variations of demand. Demand may be constant, time varying, price dependent, stock dependent etc. In 1915, the classical EOQ (Economic Order Quantity) was developed where the demand rate of an item was taken as constant. Wagner and Whitin [1] discussed the discrete case of the dynamic version of EOQ. Ghare and Schrader [2] developed an EOQ model with an exponential decaying inventory in modified form. Shah and Jaiswal [3] presented an order-level inventory model for deteriorating items with a constant rate of deterioration. Aggarwal [4] developed an orderlevel inventory model by correcting and modifying the error in Shah and Jaiswal's analysis [3] in calculating the average inventory holding cost. This model was extended by Covert and Philip [5] by considering Weibull distribution deterioration. Then, Philip [6] extended the model by considering a variable deterioration rate of three-parameter Weibull distribution. Generally, credit period shows that a time period in which a supplier permits the customer to settle the total amount owed to him. In the permissible delay period, it is found that interest is not charged from customer. Many inventory modelers have paid their attention for time-dependent demand. Silver and Meal [7] first suggested a simple modification of the EOQ for the case of a varying demand. However, Donaldson [8] was the first to give a fully analytical treatment to the problem of inventory replenishment with a linearly time-dependent demand. Many researchers like Silver [9], Ritchie [10-12], Mitra, Cox and Jesse [13], etc., made valuable contributions in this direction. Researchers then developed inventory models for deteriorating items with trended demand. Notable works in this direction came from researchers like Dave and Patel [14], Bahari-Kasani [15], Chung and Ting [16], Gowsami and Chaudhuri [17], Hariga [18], Jalan, Giri and Chaudhuri [19], Giri, Goswami and Chaudhuri [20], Jalan and Chaudhuri [21], Lin, Tan and Lee [16] and others. Some researchers like Wee [17] and Jalan and Chaudhuri [18] developed their model taking exponentially time varying demand pattern. Many inventory items (for example, electronic goods, fashionable clothes, etc.) as they experience fluctuations in the demand rate. Many products experience a period of rising demand during the growth phase of their product life cycle. On the other hand, the demand of some products may decline due to the introduction of more attractive products influencing customers' preference. Moreover, the age of the inventory has a negative impact on demand due to loss of consumer confidence on the quality of such products and physical loss of materials. This phenomenon prompted many researchers to develop deteriorating inventory models with time varying demand pattern. In developing inventory models, two kinds of 
time varying demands have been considered so far: (a) continuous-time and (b) discrete-time. Most of the continuous-time inventory models have been developed considering either linearly increasing/decreasing demand or exponentially increasing/decreasing demand patterns. The consideration of exponentially decreasing demand for an inventory model was first proposed by Hollier and Mak [19], who obtained optimal replenishment policies under both constant and variable replenishment intervals. Hariga and Benkherouf [20] generalized Hollier and Mak's model [19] by taking into account both exponentially growing and declining markets. Wee [21, 22] developed a deterministic lot size model for deteriorating items where demand declines exponentially over a fixed time horizon. Wee [22] presented a deteriorating inventory model where demand decreases exponentially with time and cost of items. In the real life situation, we see that suppliers offer their customer a certain credit period with interest during the permissible delay period. Inventory models with permissible delay in payments were $1^{\text {st }}$ studied by Goyal [23]. Shinn et al. [24] extended Goyal's [23] models and considered quantity discount for freight cost. Chu et al. [25] and Chung, Chang and Yang[26] also extended Goyal's [23] models for the case of deteriorating item. Many researchers like Davis \& Gaither [27], Mondal and Phaujder [28], Aggarwal \& Jagging [29], Chang, Hung, and Dye, C.Y.[30], Chung and Liao [31] developed inventory model considering delay in payment. Sana and Chaudhury[32] developed a more general EOQ model with delay in payments, price-discount effect and different types of demand rate. Recently, Khanra, Ghosh and Chaudhuri developed an EOQ model for a deteriorating item with time dependent quadratic demand under permissible delay in payment.

In this paper, an effort has been made to analyze an EOQ model for deteriorating item considering timedependent exponentially declining demand rate and permissible delay in payment. The proposed model is based on inventory items (for example, electronic goods, fashionable clothes, etc.) as they experience fluctuations in the demand rate. Among the various time-varying demands in EOQ models, the more realistic demand approach is to consider an exponentially declining demand rate. Mathematical models have been derived under two different circumstances: Case I: The credit period is less than or equal to the cycle time for settling the account and Case II: The credit period is greater than the cycle time for settling the account. The models are illustrated with numerical examples. Also the sensitivity analysis of the model is examined for changes in the parameters.

\section{Assumptions And Notations}

The following assumptions are made in developing the model.

(i) The demand rate for the item is represented by an exponential and continuous function of time.

(ii) Replenishment rate is infinite, i. e., replenishment rate is instantaneous.

(iii) Shortage is not allowed.

(iv) The deterioration rate is constant on the on-hand inventory per unit time and there is no repair or replenishment of the deteriorated items within the cycle.

(v) Time horizon is infinite.

The following notations have been used in developing the model.

(i) The time dependent demand rate is $D(t)=K e^{-\gamma t}, K>0, \gamma \neq 0$.

(ii) $p$ is the unit purchase cost of item.

(iii) $h_{p}$ is the inventory holding cost (excluding interest charges) per rupee of unit purchase cost per unit time.

(iv) $\theta(0<\theta<1)$ is the constant rate of deterioration of an item.

(v) $A$ is the replenishment cost.

(vi) $I_{p}$ is the interest charges per rupee investment in stock per year.

(vii) $I_{e}$ is the interest earned per rupee in a year.

(viii) $t_{1}$ is the permissible period (in year) of delay in settling the accounts with the supplier.

(ix) $T$ is the time interval (in year between two successive orders).

\section{Formulation And Solution Of The Model}

The instantaneous inventory level $I(t)$ at any time $t$ during the cycle time $t$ is governed by the following differential equation

$\frac{d I(t)}{d t}+\theta I(t)=-D(t), \quad 0 \leq t \leq T$,

with $I(0)=I_{0}$ and $I(T)=0$, and $D(t)=K e^{-\gamma t}$ where $K(>0)$ is initial demand and $\gamma(0<\gamma<\theta)$ is a constant governing the decreasing rate of the demand.

The solution of the Eq. (1) is

$I(t)=\frac{K}{(\theta-\gamma)}\left[e^{(\theta-\gamma) T-\theta t}-e^{-\gamma t}\right], \quad 0 \leq t \leq T$.

If $\gamma=0$, then Eq. (2) represents the instantaneous inventory level at any time $t$ for the constant demand rate. The initial order quantity is

$I_{0}=I(0)=\frac{K}{(\theta-\gamma)}\left[e^{(\theta-\gamma) T}-1\right]$. 
The total demand during the cycle period $[0, T]$ is

$\begin{aligned} \int_{0}^{T} D(t) d t & =\int_{0}^{T}\left(K e^{-\gamma t}\right) d t \\ & =\frac{K}{\gamma}\left(1-e^{-\gamma T}\right) .\end{aligned}$

Number of deteriorated units is

$I_{0}-\int_{0}^{T} D(t) d t=K\left[\frac{1}{(\theta-\gamma)}\left(e^{(\theta-\gamma) T}-1\right)+\frac{1}{\gamma}\left(e^{-\gamma T}-1\right)\right]$.

Deterioration cost for the cycle $[0, T]=p \times$ (number of deteriorated units)

$=p K\left[\frac{1}{(\theta-\gamma)}\left(e^{(\theta-\gamma) T}-1\right)+\frac{1}{\gamma}\left(e^{-\gamma T}-1\right)\right]$.

Total holding cost for the cycle $[0, T]$ is

$$
\begin{aligned}
H C & =h \int_{0}^{T} I(t) d t \\
& =h \int_{0}^{T}\left[\frac{K}{(\theta-\gamma)}\left(e^{(\theta-\gamma) T-\theta t}-e^{-\gamma t}\right)\right] d t \\
& =\frac{h K}{(\theta-\gamma)}\left[\frac{1}{\theta}\left(e^{(\theta-\gamma) T}-e^{-\gamma T}\right)+\frac{1}{\gamma}\left(e^{-\gamma T}-1\right)\right], \text { where } h=h_{p} \cdot p .
\end{aligned}
$$

Case -1: let $T>t_{1}$.

Since the interest is payable during the time $\left(T-t_{1}\right)$, the interest payable in any cycle $[0, T]$ is $I P_{1}=p I_{p} \int_{t_{1}}^{T} I(t) d t$

$$
\begin{aligned}
& =p I_{p} \int_{t_{1}}^{T}\left[\frac{K}{(\theta-\gamma)}\left(e^{(\theta-\gamma) T-\theta t}-e^{-\gamma t}\right)\right] d t \\
& =\frac{p I_{p} K}{(\theta-\gamma)}\left[\frac{1}{\theta}\left(e^{(\theta-\gamma) T-\theta t_{1}}-e^{-\gamma t}\right)+\frac{1}{\gamma}\left(e^{-\gamma T}-e^{-\gamma t_{1}}\right)\right] .
\end{aligned}
$$

Interest earned in the cycle period $[0, T]$ is

$$
\begin{aligned}
I E_{1} & =p I_{e} \int_{0}^{T} t D(t) d t \\
& =\frac{p I_{p} K}{\gamma}\left[\frac{1}{\gamma}\left(1-e^{-\gamma T}\right)-T e^{-\gamma T}\right] .
\end{aligned}
$$

Total variable cost per cycle $=$ replenishment cost + inventory holding cost + deterioration cost + inventory payable during the permissible delay period - interest earned during the cycle.

So, the total variable cost per unit time is

$$
\begin{aligned}
Z_{1}(T)=\frac{A}{T} & +\frac{h K}{(\theta-\gamma) T}\left[\frac{1}{\theta}\left(e^{(\theta-\gamma) T}-e^{-\gamma T}\right)+\frac{1}{\gamma}\left(e^{-\gamma T}-1\right)\right] \\
& +\frac{p K}{T}\left[\frac{1}{(\theta-\gamma)}\left(e^{(\theta-\gamma) T}-1\right)+\frac{1}{\gamma}\left(e^{-\gamma T}-1\right)\right] \\
& +\frac{p I_{p} K}{(\theta-\gamma)}\left[\frac{1}{\theta}\left(e^{(\theta-\gamma) T-\theta t_{1}}-e^{-\gamma t}\right)+\frac{1}{\gamma}\left(e^{-\gamma T}-e^{-\gamma t_{1}}\right)\right] \\
& -\frac{p I_{e} K}{\gamma T}\left[\frac{1}{\gamma}\left(1-e^{-\gamma T}\right)-T e^{-\gamma T}\right] .
\end{aligned}
$$

Our aim is to find minimum variable cost per unit time.

The necessary and sufficient conditions to minimize $Z_{1}(T)$ for a given value $t_{1}$ are respectively $\frac{d Z_{1}(T)}{d T}=0$ and $\frac{d^{2} Z_{1}(T)}{d T^{2}}>0$.

Now $\frac{d Z_{1}(T)}{d T}=0$ gives the following non-linear equation in $T$ :

$\frac{1}{T}\left[K e^{-\gamma t}\left[\frac{(h+\theta p)}{\theta}\left(e^{\theta T}-1\right)+\frac{p I_{p}}{\theta}\left(e^{\theta\left(T-t_{1}\right)}-1\right)-p I_{e} T\right]-Z_{1}(T)\right]=0$.

To get the optimal cycle length $T=T_{1}$, we have to solve Eq. (9) provided it satisfies the following condition $\frac{d^{2} Z_{1}(T)}{d T^{2}}>0$.

The EOQ in this case is as follows:

$$
I_{0}\left(T_{1}\right)=\frac{K}{(\theta-\gamma)}\left[e^{(\theta-\gamma) T_{1}}-1\right] .
$$

Case -2: let $T<t_{1}$.

In this case the customer earns interest on the sales revenue up to the permissible delay period and no interest is payable during the period for the item kept in stock.

Interest earned for the time period $[0, T]$ is

$$
p I_{e} \int_{0}^{T} t D(t) d t=\frac{p I_{e} K}{\gamma}\left[\frac{1}{\gamma}\left(1-e^{-\gamma T}\right)-T e^{-\gamma T}\right] .
$$

Interest earned for the permissible period $\left[T, t_{1}\right]$ is

$p I_{e}\left(t_{1}-T\right) \int_{0}^{T} D(t) d t=\frac{p I_{e}\left(t_{1}-T\right) K}{\gamma}\left(1-e^{-\gamma T}\right)$.

Hence the total interest earned during the cycle $=$ Interest earned for the time period $[0, T]+$ Interest earned for the permissible period $\left[T, t_{1}\right]$, i. e.,

$I E_{2}=p I_{e} \int_{0}^{T} t D(t) d t+p I_{e}\left(t_{1}-T\right) \int_{0}^{T} D(t) d t$ 
In this case, the total variable cost per cycle $=$ replenishment cost + inventory holding cost + deterioration cost interest earned during the cycle.

Hence the total variable cost per cycle per unit time is

$$
\begin{aligned}
Z_{2}(T)=\frac{A}{T} & +\frac{h K}{(\theta-\gamma) T}\left[\frac{1}{\theta}\left(e^{(\theta-\gamma) T}-e^{-\gamma T}\right)+\frac{1}{\gamma}\left(e^{-\gamma T}-1\right)\right] \\
& +\frac{p K}{T}\left[\frac{1}{(\theta-\gamma)}\left(e^{(\theta-\gamma) T}-1\right)+\frac{1}{\gamma}\left(e^{-\gamma T}-1\right)\right] \\
& -\frac{p I_{e} K}{\gamma T}\left[\left(\frac{1}{\gamma}+t_{1}-T\right)\left(1-e^{-\gamma T}\right)-T e^{-\gamma T}\right] .
\end{aligned}
$$

As before, we have to minimize $Z_{2}(T)$ for a given value of $t_{1}$.

The necessary and the sufficient conditions to minimize $Z_{2}(T)$ for a given value $t_{1}$ are respectively $\frac{d Z_{2}(T)}{d T}=0$ and $\frac{d^{2} Z_{2}(T)}{d T^{2}}>0$.

Now $\frac{d Z_{2}(T)}{d T}=0$ gives the following non-linear equation in $T$ :

$\frac{1}{T}\left[K e^{-\gamma t}\left[\frac{(h+\theta p)}{\theta}\left(e^{\theta T}-1\right)-\frac{p I_{e}}{\gamma}\left(\left(1+\gamma t_{1}\right)-e^{\gamma T}\right)\right]-Z_{2}(T)\right]=0$.

The EOQ in this case is as follows:

$I_{0}\left(T_{2}\right)=\frac{K}{(\theta-\gamma)}\left[e^{(\theta-\gamma) T_{2}}-1\right]$.

The minimum annual cost is $Z_{2}\left(T_{2}{ }^{*}\right)$ is obtained from Eq. (14) for $T=T_{2}$.

Case -3: let $T=t_{1}$.

For $T=t_{1}$, both the cost function $Z_{1}(T)$ and $Z_{2}(T)$ are identical and the cost function is obtained by putting $T=t_{1}$ either in Eq. (8) or in Eq. (14) and is given by

$$
\begin{aligned}
Z_{3}\left(t_{1}\right)=\frac{A}{t_{1}} & +\frac{h K}{(\theta-\gamma) t_{1}}\left[\frac{1}{\theta}\left(e^{(\theta-\gamma) t_{1}}-e^{-\gamma t_{1}}\right)+\frac{1}{\gamma}\left(e^{-\gamma t_{1}}-1\right)\right] \\
& +\frac{p K}{t_{1}}\left[\frac{1}{(\theta-\gamma)}\left(e^{(\theta-\gamma) t_{1}}-1\right)+\frac{1}{\gamma}\left(e^{-\gamma t_{1}}-1\right)\right] \\
& -\frac{p I_{e} K}{\gamma t_{1}}\left[\frac{1}{\gamma}\left(1-e^{-\gamma t_{1}}\right)-t_{1} e^{-\gamma t_{1}}\right] .
\end{aligned}
$$

The EOQ in this case is as follows:

$I_{0}\left(t_{1}\right)=\frac{K}{(\theta-\gamma)}\left[e^{(\theta-\gamma) t_{1}}-1\right]$

\section{Solution Of Economic Order Policy: Algorithm}

The following steps to be followed to be find the optimum cost and economic order quantity unless $T=T_{1}$.

Step -1: Determine $T_{1}^{*}$ from Eq. (9). If $T_{1}^{*}>t_{1}$, evaluate $Z_{1}\left(T_{1}^{*}\right)$ from Eq. (8).

Step -2: Determine $T_{2}^{*}$ from Eq. (15). If $T_{1}^{*}<t_{1}$, evaluate $Z_{2}\left(T_{2}^{*}\right)$ from Eq. (14).

Step -3: if the condition $T_{1}^{*}>t_{1}>T_{2}^{*}$ is satisfied, then go to Step -4. Otherwise go to Step -5.

Step -4: Compare $Z_{1}\left(T_{1}^{*}\right)$ and $Z_{2}\left(T_{2}^{*}\right)$ and find the minimum cost.

Step -5: If the condition $T_{1}^{*}>t_{1}$ is satisfied but $T_{2}^{*}>t_{1}$, then $Z_{1}\left(T_{1}^{*}\right)$ is the minimum cost, else if $T_{1}^{*}<t_{1}$ but $T_{2}^{*}<t_{1}$ then $Z_{2}\left(T_{2}^{*}\right)$ is the minimum cost.

Step -6: Compute $I_{0}^{*}\left(t_{1}\right)$ or $I_{0}^{*}\left(t_{2}\right)$ for the respective minimum cost.

\section{Numerical Examples}

The numerical examples given below cover all the three cases that arise in the model.

\section{Example -1: (Case -I:)}

Let us consider the parameter values of the system as $K=500$ units per year, $\gamma=0.1$ units per year, $A=$ $R s .200$ per order, $I_{p}=0.15$ per year, $I_{e}=0.13$ per year, $h=R s .0 .12$ per year, $p=R s .20$ per unit, $\theta=0.20$ and $t_{1}=0.05$ year.

Solving Eq. (9), we have $T_{1}^{*}=0.416761$ year and the minimum average cost is $Z_{1}\left(T_{1}^{*}\right)=R s .886 .62$.

Again solving Eq. (15), we have $T_{2}^{*}=0.346202$ year and the minimum average cost is $Z_{2}\left(T_{2}^{*}\right)=R s$. 1092.89. Here $T_{2}^{*}>t_{1}$ which contradicts Case - II. Only Case-I holds as $T_{1}^{*}>t_{1}$. Hence the minimum average cost in this case is $Z_{1}\left(T_{1}^{*}\right)=R s .886 .62$ where the optimum cycle length is $T_{1}^{*}=0.416761$ year.

The economic order quantity is given by $I_{0}^{*}\left(T_{1}^{*}\right)=212.784$.

Example -2: (Case -I and Case-II:), Minimum average cost is $Z_{1}\left(T_{1}^{*}\right)$.

Let us consider the parameter values of the system as $K=500$ units per year, $\gamma=0.1$ units per year, $A=$ $R s .200$ per order, $I_{p}=0.15$ per year, $I_{e}=0.13$ per year, $h=R s .0 .12$ per year, $p=R s .20$ per unit, $\theta=0.20$ and $t_{1}=0.35$ year.

Solving Eq. (9), we have $T_{1}^{*}=0.501679$ year and the minimum average cost is $Z_{1}\left(T_{1}^{*}\right)=R s .633 .32$. 
Again solving Eq. (15), we have $T_{2}^{*}=0.344233$ year and the minimum average cost is $Z_{2}\left(T_{2}^{*}\right)=R s .709 .54$.

Here $Z_{1}\left(T_{1}^{*}\right)<Z_{2}\left(T_{2}^{*}\right)$.

Hence the minimum average cost in this case is $Z_{1}\left(T_{1}^{*}\right)=R s .633 .32$ where the optimum cycle length is $T_{1}^{*}=0.501679$ year.

The economic order quantity is given by $I_{0}^{*}\left(T_{1}^{*}\right)=257.238$.

Example -3: (Case -I and Case-II:), Minimum average cost is $Z_{2}\left(T_{2}^{*}\right)$.

Let us consider the parameter values of the system as $K=500$ units per year, $\gamma=0.1$ units per year, $A=$ $R s .200$ per order, $I_{p}=0.15$ per year, $I_{e}=0.13$ per year, $h=R s .0 .12$ per year, $p=R s .20$ per unit, $\theta=0.20$ and $t_{1}=0.5$ year.

Solving Eq. (9), we have $T_{1}^{*}=0.575452$ year and the minimum average cost is $Z_{1}\left(T_{1}^{*}\right)=$ Rs. 587.49.

Again solving Eq. (15), we have $T_{2}^{*}=0.343261$ year and the minimum average cost is $Z_{2}\left(T_{2}^{*}\right)=R s .517 .85$.

Here $T_{1}^{*}>t_{1}$ and $T_{2}^{*}<t_{1}$ both hold and these imply that both the cases Case - I and II hold.

Now $Z_{2}\left(T_{2}^{*}\right)<Z_{1}\left(T_{1}^{*}\right)$.

Hence the minimum average cost in this case is $Z_{2}\left(T_{2}^{*}\right)=R s .517 .85$ where the optimum cycle length is $T_{2}^{*}=0.343261$ year.

The economic order quantity is given by $I_{0}^{*}\left(T_{2}^{*}\right)=174.61$.

Example -4: (Case -II:)

Let us consider the parameter values of the system as $K=500$ units per year, $\gamma=0.1$ units per year, $A=$ $R s .200$ per order, $I_{p}=0.15$ per year, $I_{e}=0.13$ per year, $h=R s .0 .12$ per year, $p=R s .20$ per unit, $\theta=0.20$ and $t_{1}=0.75$ year.

Solving Eq. (9), we have $T_{1}^{*}=0.721147$ year and the minimum average cost is $Z_{1}\left(T_{1}^{*}\right)=$ Rs. 574.43.

Again solving Eq. (15), we have $T_{2}^{*}=0.34166$ year and the minimum average cost is $Z_{2}\left(T_{2}^{*}\right)=R s .198 .36$.

Here $T_{1}^{*}<t_{1}$ which contradicts Case $-\mathrm{I}$. Only Case-II holds as $T_{2}^{*}<t_{1}$. Hence the minimum average cost in this case is $Z_{2}\left(T_{2}^{*}\right)=R s .198 .36$ where the optimum cycle length is $T_{2}^{*}=034166$ year.

The economic order quantity is given by $I_{0}^{*}\left(T_{2}^{*}\right)=173.782$.

Example -5 (Case -III:)

Let us consider the parameter values of the system as $K=500$ units per year, $\gamma=0.1$ units per year, $A=$ $R s .200$ per order, $I_{p}=0.15$ per year, $I_{e}=0.13$ per year, $h=R s .0 .12$ per year, $p=R s .20$ per unit, $\theta=0.20$ and $t_{1}=T$ year.

Solving Eq. (16), we have $T_{1}^{*}=T_{2}^{*}=t_{1}^{*}=0.676052$ years which is case - III.

Hence the minimum average cost in this case is $Z_{1}\left(t_{1}^{*}\right)=R s .572 .31$ where the optimum cycle length is $t_{1}^{*}=0.676052$ year.

The economic order quantity is given by $I_{0}^{*}\left(t_{1}{ }^{*}\right)=349.714$.

\section{Sensitivity Analysis}

We now study the effect of changes in the values of he system parameters $K, \gamma, A, I_{p}, I_{e}, h, p, \theta$ and $t_{1}$ on the optimal cost and number of reorder. The sensitivity analysis is performed by changing each of the parameters by $50 \%, 10 \%,-10 \%$ and $-50 \%$ taking one parameter at a time and keeping the remaining parameters unchanged.

The analysis is based on the Example -1 and the results are shown in the table -1 . The following points are observed.

(i) $\quad T_{1}^{*} \& T_{2}^{*}$ decrease while $Z_{1}\left(T_{1}^{*}\right) \& Z_{2}\left(T_{2}^{*}\right)$ increase with the increase in value of the parameter $K$. Both $T_{2}^{*}$ $\& Z_{2}\left(T_{2}^{*}\right)$ are moderately sensitivity to changes in $K$.

(ii) $\quad T_{1}^{*} \& T_{2}^{*}$ increase while $Z_{1}\left(T_{1}^{*}\right) \& Z_{2}\left(T_{2}^{*}\right)$ decrease with the increase in value of the parameter $\gamma$. Both $T_{1}^{*}$ $\& T_{2}^{*}$ are low sensitivity to changes in $\gamma$ and $Z_{1}\left(T_{1}^{*}\right) \& Z_{2}\left(T_{2}^{*}\right)$ are moderately sensitivity to changes in $\gamma$.

(iii) $T_{1}^{*}$ decreases while $Z_{1}\left(T_{1}^{*}\right)$ increases with the increase in value of the parameter $I_{p}$. Both $T_{1}^{*} \& Z_{1}\left(T_{1}^{*}\right)$ are moderately sensitivity to changes in $I_{p}$ and both $T_{2}^{*} \& Z_{2}\left(T_{2}^{*}\right)$ are insensitivity to changes in $I_{p}$.

(iv) $T_{1}^{*} \& Z_{2}\left(T_{2}^{*}\right)$ increase while $T_{2}^{*} \& Z_{1}\left(T_{1}^{*}\right)$ decrease with the increase in value of the parameter $I_{e}$. Both $T_{2}{ }^{*} \& Z_{2}\left(T_{2}^{*}\right)$ are moderately sensitivity to changes in $I_{e}$.

(v) $T_{1}^{*} \& T_{2}^{*}$ decrease while $Z_{1}\left(T_{1}^{*}\right) \& Z_{2}\left(T_{2}^{*}\right)$ increase with the increase in value of the parameter $h . T_{1}^{*}, T_{2}^{*}$, $Z_{1}\left(T_{1}^{*}\right) \& Z_{2}\left(T_{2}^{*}\right)$ are low sensitivity to changes in $h$.

(vi) $\quad T_{1}^{*} \& T_{2}^{*}$ decrease while $Z_{1}\left(T_{1}^{*}\right) \& Z_{2}\left(T_{2}^{*}\right)$ increase with the increase in value of the parameter $p$. Both $T_{2}^{*}$ $\& Z_{2}\left(T_{2}^{*}\right)$ are moderately sensitivity to changes in $p$.

(vii) $T_{1}^{*}$ increases while $T_{2}^{*}, Z_{1}\left(T_{1}^{*}\right) \& Z_{2}\left(T_{2}^{*}\right)$ decrease with the increase in value of the parameter $t_{1}$. Both $T_{1}^{*}$ $\& T_{2}^{*}$ are low sensitivity to changes in $t_{1}$ and $Z_{1}\left(T_{1}^{*}\right) \& Z_{2}\left(T_{2}^{*}\right)$ are moderately sensitivity to changes in $t_{1}$.

(viii) $T_{1}^{*} \& T_{2}^{*}$ decrease while $Z_{1}\left(T_{1}^{*}\right) \& Z_{2}\left(T_{2}^{*}\right)$ increase with the increase in value of the parameter $\theta . T_{1}^{*}, T_{2}^{*}$ $\& Z_{1}\left(T_{1}^{*}\right)$ are moderately sensitivity to changes in $\theta$ and $Z_{2}\left(T_{2}^{*}\right)$ are highly sensitivity to changes in $\theta$. 
An EOQ Model for a Deteriorating Item with Time Dependent Exponentially Declining Demand

(ix) $T_{1}^{*}, T_{2}^{*}, Z_{1}\left(T_{1}^{*}\right) \& Z_{2}\left(T_{2}^{*}\right)$ increase with the increase in value of the parameter $A$. Both $T_{1}^{*} \& T_{2}^{*}$ are moderately sensitivity to changes in $A$ and $Z_{1}\left(T_{1}^{*}\right) \& Z_{2}\left(T_{2}^{*}\right)$ are highly sensitivity to changes in $A$.

However, this outcome may be due to the choice of the particular parameter values in this numerical example. From the Table -1 , it is found that optimum cost decreases rapidly with the increase of the parameter $\gamma$ and $t_{1}$ which justify the real market situation.

Table -1.

\begin{tabular}{|c|c|c|c|c|c|c|c|c|}
\hline Parameter & $\begin{array}{l}\% \\
\text { Change in } \\
\text { parameter }\end{array}$ & $T_{1}{ }^{*}$ & $Z_{1}\left(T_{1}^{*}\right)$ & $T_{2}{ }^{*}$ & $Z_{2}\left(T_{2}{ }^{*}\right)$ & Remark & Solution & $\begin{array}{l}\% \\
\text { Change } \\
\text { in } \\
\text { optimum } \\
\text { cost }\end{array}$ \\
\hline$K$ & $\begin{array}{l}+50 \\
+10 \\
-10 \\
-50\end{array}$ & $\begin{array}{l}\ldots \\
\ldots \\
\ldots \\
0.584407\end{array}$ & $\begin{array}{l}\ldots \\
\ldots \\
\ldots \\
642.97\end{array}$ & $\begin{array}{l}0.282452 \\
0.330025 \\
0.365012 \\
\ldots\end{array}$ & $\begin{array}{l}1321.18 \\
1143.03 \\
1039.84 \\
\ldots\end{array}$ & $\begin{array}{l}T_{2}{ }^{*} \\
>t_{1} \\
T_{2}{ }^{*} \\
>t_{1} \\
T_{2}{ }^{*} \\
>t_{1} \\
T_{1}{ }^{*} \\
>t_{1}\end{array}$ & $\begin{array}{l}Z_{2}\left(T_{2}{ }^{*}\right) \\
Z_{2}\left(T_{2}{ }^{*}\right) \\
Z_{2}\left(T_{2}{ }^{*}\right) \\
Z_{1}\left(T_{1}{ }^{*}\right)\end{array}$ & $\begin{array}{l}\cdots \\
\cdots \\
\cdots \\
\cdots\end{array}$ \\
\hline$\gamma$ & $\begin{array}{l}+50 \\
+10 \\
-10 \\
-50\end{array}$ & $\begin{array}{l}0.422221 \\
\ldots \\
0.415697 \\
\ldots\end{array}$ & $\begin{array}{l}880.72 \\
\ldots \\
887.79 \\
\ldots\end{array}$ & $\begin{array}{l}0.349322 \\
0.346819 \\
0.345588 \\
0.343167\end{array}$ & $\begin{array}{l}1088.03 \\
1091.92 \\
1093.86 \\
1097.72\end{array}$ & $\begin{array}{l}T_{1}{ }^{*} \\
>t_{1} \\
T_{2}{ }^{*} \\
>t_{1} \\
T_{1}{ }^{*} \\
>t_{1} \\
T_{2}{ }^{*} \\
>t_{1}\end{array}$ & $\begin{array}{l}Z_{1}\left(T_{1}{ }^{*}\right) \\
Z_{2}\left(T_{2}{ }^{*}\right) \\
Z_{1}\left(T_{1}{ }^{*}\right) \\
Z_{2}\left(T_{2}{ }^{*}\right)\end{array}$ & $\begin{array}{l}-0.67 \\
\ldots \\
+0.13 \\
\ldots\end{array}$ \\
\hline$I_{p}$ & $\begin{array}{l}+50 \\
+10 \\
-10 \\
-50\end{array}$ & $\begin{array}{l}0.40435 \\
\ldots \\
0.502333\end{array}$ & $\begin{array}{l}910.24 \\
\ldots \\
751.87 \\
\ldots\end{array}$ & $\begin{array}{l}0.346202 \\
0.346202 \\
0.346202 \\
0.346202\end{array}$ & $\begin{array}{l}1092.89 \\
1092.89 \\
1092.89 \\
1092.89\end{array}$ & $\begin{array}{l}T_{2}{ }^{*} \\
>t_{1} \\
T_{1}{ }^{*} \\
>t_{1} \\
T_{2}{ }^{*} \\
>t_{1} \\
T_{1}{ }^{*} \\
>t_{1}\end{array}$ & $\begin{array}{l}Z_{2}\left(T_{2}{ }^{*}\right) \\
Z_{1}\left(T_{1}^{*}\right) \\
Z_{2}\left(T_{2}{ }^{*}\right) \\
Z_{1}\left(T_{1}{ }^{*}\right)\end{array}$ & $\begin{array}{l}\ldots \\
+2.66 \\
\ldots \\
-15.2\end{array}$ \\
\hline$I_{e}$ & $\begin{array}{l}+50 \\
+10 \\
-10 \\
-50\end{array}$ & $\begin{array}{l}\ldots \\
\ldots \\
0.406293 \\
\ldots\end{array}$ & $\begin{array}{l}\ldots \\
\ldots \\
912.64 \\
\ldots\end{array}$ & $\begin{array}{l}\ldots \\
0.339735 \\
0.353047 \\
\ldots\end{array}$ & $\begin{array}{l}\ldots \\
1108.54 \\
1076.82 \\
\ldots\end{array}$ & $\begin{array}{l}\cdots \\
T_{2}{ }^{*} \\
>t_{1} \\
T_{1}{ }^{*} \\
>t_{1}\end{array}$ & $\begin{array}{l}\cdots \\
Z_{2}\left(T_{2}{ }^{*}\right) \\
Z_{1}\left(T_{1}{ }^{*}\right) \\
\cdots\end{array}$ & $\begin{array}{l}\ldots \\
\ldots \\
+2.93 \\
\ldots\end{array}$ \\
\hline$h$ & $\begin{array}{l}+50 \\
+10 \\
-10 \\
-50\end{array}$ & $\begin{array}{l}0.416232 \\
0.417292 \\
0.419436\end{array}$ & $\begin{array}{l}\ldots \\
887.87 \\
885.37 \\
880.35\end{array}$ & $\begin{array}{l}0.344649 \\
0.345889 \\
0.346515 \\
0.347775\end{array}$ & $\begin{array}{l}1098.07 \\
1093.93 \\
1091.85 \\
1087.68\end{array}$ & $\begin{array}{l}T_{2}{ }^{*} \\
>t_{1} \\
T_{1}{ }^{*} \\
>t_{1} \\
T_{1}{ }^{*} \\
>t_{1} \\
T_{1}{ }^{*} \\
>t_{1}\end{array}$ & $\begin{array}{l}Z_{2}\left(T_{2}{ }^{*}\right) \\
Z_{1}\left(T_{1}{ }^{*}\right) \\
Z_{1}\left(T_{1}^{*}\right) \\
Z_{1}\left(T_{I}^{*}\right)\end{array}$ & $\begin{array}{l}\ldots \\
+0.14 \\
-0.14 \\
-0.71\end{array}$ \\
\hline$p$ & $\begin{array}{l}+50 \\
+10 \\
-10 \\
-50\end{array}$ & $\begin{array}{l}\ldots \\
\ldots \\
\ldots \\
0.577238\end{array}$ & $\begin{array}{l}\ldots \\
\ldots \\
\ldots \\
651.69\end{array}$ & $\begin{array}{l}0.283304 \\
0.330296 \\
0.364646 \\
\ldots\end{array}$ & $\begin{array}{l}1316.94 \\
1142.04 \\
1040.94 \\
\ldots\end{array}$ & $\begin{array}{l}T_{2}{ }^{*} \\
>t_{1} \\
T_{2}{ }^{*} \\
>t_{1} \\
T_{2}{ }^{*} \\
>t_{1} \\
T_{1}{ }^{*} \\
>t_{1}\end{array}$ & $\begin{array}{l}Z_{2}\left(T_{2}{ }^{*}\right) \\
Z_{2}\left(T_{2}{ }^{*}\right) \\
Z_{2}\left(T_{2}{ }^{*}\right) \\
Z_{1}\left(T_{1}{ }^{*}\right)\end{array}$ & $\begin{array}{l}\cdots \\
\cdots \\
\cdots \\
\cdots\end{array}$ \\
\hline
\end{tabular}


An EOQ Model for a Deteriorating Item with Time Dependent Exponentially Declining Demand

\begin{tabular}{|c|c|c|c|c|c|c|c|c|}
\hline$t_{1}$ & $\begin{array}{l}+50 \\
+10 \\
-10 \\
-50\end{array}$ & $\begin{array}{l}0.419452 \\
0.417225 \\
0.416335 \\
\ldots\end{array}$ & $\begin{array}{l}854.36 \\
879.98 \\
893.36 \\
\ldots\end{array}$ & $\begin{array}{l}0.346036 \\
0.346169 \\
0.346235 \\
0.346367\end{array}$ & $\begin{array}{l}1060.95 \\
1086.5 \\
1099.28 \\
1124.83\end{array}$ & $\begin{array}{l}T_{1}{ }^{*} \\
>t_{1} \\
T_{1}{ }^{*} \\
>t_{1} \\
T_{1}{ }^{*} \\
>t_{1} \\
T_{1}{ }^{*} \\
>t_{l}\end{array}$ & $\begin{array}{l}Z_{1}\left(T_{1}^{*}\right) \\
Z_{1}\left(T_{1}{ }^{*}\right) \\
Z_{1}\left(T_{1}{ }^{*}\right) \\
Z_{2}\left(T_{2}{ }^{*}\right)\end{array}$ & $\begin{array}{l}-3.64 \\
-0.75 \\
+0.76 \\
\ldots\end{array}$ \\
\hline$\theta$ & $\begin{array}{l}+50 \\
+10 \\
-10 \\
-50\end{array}$ & $\begin{array}{l}0.39867 \\
0.437466 \\
\ldots\end{array}$ & $\begin{array}{l}929.21 \\
842.16 \\
\ldots\end{array}$ & $\begin{array}{l}0.335742 \\
0.357634 \\
\ldots\end{array}$ & $\begin{array}{l}1127.87 \\
1056.93 \\
\ldots\end{array}$ & $\begin{array}{l}T_{1}{ }^{*} \\
>t_{1} \\
T_{1}{ }^{*} \\
>t_{1}\end{array}$ & $\begin{array}{l}Z_{I}\left(T_{1}^{*}\right) \\
Z_{I}\left(T_{I}^{*}\right) \\
\ldots\end{array}$ & $\begin{array}{l}+4.81 \\
-5.01 \\
\ldots\end{array}$ \\
\hline$A$ & $\begin{array}{l}+50 \\
+10 \\
-10 \\
-50\end{array}$ & $\begin{array}{l}0.507926 \\
0.436598 \\
\ldots \\
\ldots\end{array}$ & $\begin{array}{l}1102.88 \\
933.5 \\
\ldots \\
\ldots\end{array}$ & $\begin{array}{l}0.42441 \\
0.363174 \\
0.328364 \\
0.244496\end{array}$ & $\begin{array}{l}1352.44 \\
1149.28 \\
1033.59 \\
754.27\end{array}$ & $\begin{array}{l}T_{1}{ }^{*} \\
>t_{1} \\
T_{1}{ }^{*} \\
>t_{1} \\
T_{2}{ }^{*} \\
>t_{1} \\
T_{2}{ }^{*} \\
>t_{1}\end{array}$ & $\begin{array}{l}Z_{1}\left(T_{1}{ }^{*}\right) \\
Z_{1}\left(T_{1}{ }^{*}\right) \\
Z_{2}\left(T_{2}{ }^{*}\right) \\
Z_{2}\left(T_{2}{ }^{*}\right)\end{array}$ & $\begin{array}{l}+24.39 \\
+5.29 \\
\ldots \\
\ldots\end{array}$ \\
\hline
\end{tabular}

“...” indicates no feasible solution.

\section{Conclusion}

The present economic order quantity (EOQ) inventory model for deteriorating items assumes an exponentially declining time-varying demand rate. The proposed model is based on inventory items (for example, electronic goods, fashionable clothes, etc.) as they experience fluctuations in the demand rate. Therefore, the advantage of the exponentially declining demand has motivated the authors to adopt it in the present model. In the real market, we see that suppliers offer their customers a certain credit period without interest during the permissible delay time period. As an outcome, it motivates customer to order more quantities because paying later indirectly reduces the purchase cost. The proposed model can be extended in several ways. For instance, it could be of interest to relax the restriction of constant deterioration rate. Also, we may extend the deterministic demand function with variable deterioration rate. Finally, we could generalize the model to the economic production lot size model.

\section{References}

[1] H. M. Wagner, T. M. Whitin, Dynamic version of the economic lot size model, Management Science, 5, 1958, 89-96.

[2] P. Ghare, G. Schrader, A model for exponential decaying inventories, Journal of Industrial Engineering, 14, 1963, $238-243$.

[3] Shah, Y.K., and Jaiswal, M.C., An order-level inventory model for a system with constant rate of deterioration, Opsearch, 14, 1977, 174-184.

[4] Aggarwal, S.P., A note on an order-level model for a system with constant rate of deterioration, Opsearch, 15, 1978, $184-187$.

[5] R. Covert, G. C. Philip, An EOQ model for items with Weibull distribution, AIIE Transactions, 5, $1973,323-326$.

[6] Philip, G.C., A generalized EOQ model for items with Weibull distribution, AIIETransactions, 6, 1974, $159-162$.

[7] E.A. Silver, H.C. Meal, A simple modification of the EOQ for the case of a varying demand rate, Production and Inventory Management, 10 (4), 1969, 52-65.

[8] W.A. Donaldson, Inventory replenishment policy for a linear trend in demand-an analytical solution, Operational Research Ouarterly, 28, 1977, 663-670.

[9] E.A. Silver, A simple inventory replenishment decision rule for a linear trend in demand, Journal of Operational Research Society, 30, 1979, 71-75.

[10] E. Ritchie, Practical inventory replenishment policies for a linear trend in demand followed by a period of steady demand, Journal of Operational Research Society, 31, 1980, 605-613.

[11] E. Ritchie, The EOQ for linear increasing demand: a simple optimal solution, Journal of Operational Research Society, 35, 1984, 949-952.

[12] E. Ritchie, Stock replenishment quantities for unbounded linear increasing demand: an interesting consequence of the optimal policy, Journal of Operational Research Society, 36, 1985, 737-739.

[13] A. Mitra, J.F. Fox, R.R. Jessejr, A note on determining order quantities with a linear trend in demand, Journal of Operational Research Society, 35, 1984, 141-144.

[14] U. Dave, L.K. Patel, (T, Si) policy inventory model for deteriorating items with time proportional demand, Journal of Operational Research Society, 32, 1981, 137-142.

[15] H. Bahari-Kashani, Replenishment schedule for deteriorating items with time-proportional demand, Journal of Operational Research Society, 40, 1989, 75-81.

[16] K.J. Chung, P.S. Ting, A heuristic for replenishment of deteriorating items with a linear trend in demand, Journal of Operational Research Society, 44(12), 1993, 1235-1241. 
[17] A. Goswami, K.S. Chaudhuri, An EOQ model for deteriorating items with a linear trend in demand, Journal of Operational Research Society, 42(12, 1991, 1105-1110.

[18] M. Hariga, An EOQ model for deteriorating items with shortages and time-varying demand, Journal of Operational Research Society, 46, 1995, 398-404.

[19] A.K. Jalan, R.R. Giri, K.S. Chaudhuri, EOQ model for items with Weibull distribution deterioration, shortages and trended demand, International Journal of Systems Science, 27(9), 1996, 851-855.

[20] B.C. Giri, A. Goswami, K.S. Chaudhuri, An EOQ model for deteriorating items with time varying demand and costs, Journal of Operational Research Society, 47, 1996, 1398-1405.

[21] A.K. Jalan, K.S. Chaudhuri, Structural properties of an inventory system with deterioration and trended demand, International Journal of Systems Science, 30(6), 1999, 627-633.

[16] C. Lin, B. Tan, W.C. Lee, An EOQ model for deteriorating items with time-varying demand and shortages, International Journal of Systems Science, 31(3), 2000, 391-400.

[17] H.M. Wee, A deterministic lot-size inventory model for deteriorating items with shortages and a declining market, Computer \& Operations Research, 22(3), 1995, 345-356.

[18] A.K. Jalan, K.S. Chaudhuri, An EOQ model for deteriorating items in a declining market with SFI policy, Korean Journal of Computational and Applied Mathematics, 6(2), 1999, 437-449.

[19] Hollier, R.H., and Mak, K.L., Inventory replenishment policies for deteriorating items in a declining market, International Journal of Production Research, 21, 1983, 813-826.

[20] Hariga, M., and Benkherouf, L., Optimal and heuristic replenishment models for deteriorating items with exponential time varying demand, European Journal of Operational Research, 79, 1994, 123-137.

[21] Wee, H.M., A deterministic lot-size inventory model for deteriorating items with shortages and a declining market, Computers and Operations Research, 22, 1995a, 345-356.

[22] Wee, H.M., Joint pricing and replenishment policy for deteriorating inventory with declining market, International Journal of Production Economics, 40, 1995b, 163-171.

[23] S.K. Goyal, EOQ under conditions of permissible delay in Payments, Journal of Operation Research Society, 36, 1985, 335-338.

[24] S.W. Shinn, H.P. Hwang, S. Sung, Joint price and lot size determination under condition of permissible delay in payments and quantity discounts for freight cost, European Journal of Operational Research, 91, 1996, 528-542.

[25] P. Chu, K.J. Chung, S.P. Lan, Economic order quantity of deteriorating items under permissible delay in payments, Computer \& Operations Research, 25, 1998, 817-824.

[26] K.J. Chung, S.L. Chang, W.D. Yang, The optimal cycle time for exponentially deteriorating products under trade credit financing, The Engineering Economist, 46, 2001, 232-242.

[27] R.A. Davis, N. Gaither, Optimal ordering policies under conditions of extended payment privileges, Management Science, 31, 1985, 499-509.

[28] B.N. Mandal, S. Phaujdar, Some EOQ models under conditions of permissible delay in payments, International Journal of Management Science, 5(2), 1989, 99-108.

[29] S.P. Aggarwal, C.K. Jaggi, Ordering policies of deteriorating items under permissible delay in payments, Journal of Operation Research Society, 36, 1995, 658-662.

[30] H.J. Chang, C.H. Hung, C.Y. Dye, An inventory model for a deteriorating items with linear trend in demand under conditions of permissible delay in payments, Production Planning and Control, 12, 2001, 272-282.

[31] K.J. Chung, J.J. Lio, Lot-sizing decisions under trade credit depending on the ordering quantity, Computer \& Operations Research, 31, 2004, 909-928.

[32] S.S. Sana, K.S. Chaudhuri, A deterministic EOQ model with delays in payments and price discount offers, European Journal of Operational Research, 184, 2008, 509-533.

[33] S. Khanra., S. K. Ghosh., K. S. Chaudhuri., An EOQ model for a deteriorating item with time dependent quadratic demand under permissible delay in payment, Applied Mathematics and Computation, 218, 2011, 1-9. 